\title{
Promesa, ejercicio y desilusión: Sancho y el gobierno de Barataria
}

Promise, exercise and disappointment: Sancho and the Barataria government

Darío G. BARRIERA

Investigaciones Sociohistóricas Regionales (ISHIR)

Universidad Nacional de Rosario (UNR), Argentina

Consejo Nacional de Investigaciones Científicas y Técnicas (CONICET), Argentina.

dgbarriera@conicet.gov.ar

\section{Resumen}

Miguel de Cervantes y Saavedra (1547-1616) fue contable, poeta, dramaturgo, soldado y, con toda seguridad, el autor más influyente del Siglo de Oro español sobre la literatura que se gestó desde entonces y construyó, a partir de sus obras, un tesoro de la lengua castellana. Pero además fue un agudo observador de su sociedad y un fenomenal intérprete del derecho, la justicia y las formas de gobierno. En este artículo se analiza un aspecto de esas observaciones: las que Cervantes vertió a través de los episodios vinculados con la promesa que Quijote hizo a su escudero, Sancho Panza, del gobierno de una ínsula, así como de la concreción de ese horizonte.

Palabras clave: Gobierno; Islas; Cervantes; Quijote; Sancho Panza.

\begin{abstract}
Miguel de Cervantes y Saavedra (1547-1616) was an accountant, poet, playwright, soldier and, with all certainty, the most influential author of the Spanish Golden Age on literature that was conceived since then and built, based on his works, a treasure of the Castilian language. But he was also a keen observer of his society and a phenomenal interpreter of law, justice and forms of government. This article analyzes one aspect of these observations: those that Cervantes made through the episodes related to the promise that Quixote made to his squire, Sancho Panza, of the government of an island, as well as the realization of that horizon.
\end{abstract}

Keywords: Government; Islands; Cervantes; Quijote; Sancho Panza. 
Bien que en su locura y en medio de aspavientos por el saqueo a la habitación de sus libros, Alonso Quijano -en la piel de don Quijote- solicitó los servicios de "...un labrador vecino suyo, hombre de bien (si es que este título se puede dar al que es pobre), pero de muy poca sal en la mollera. En resolución, tanto le dijo, tanto le persuadió y prometió, que el pobre villano se determinó de salirse con él y servirle de escudero. Decíale, entre otras cosas, don Quijote que se dispusiese a ir con él de buena gana, porque tal vez le podía suceder aventura, que ganase, en quítame allá esas pajas, alguna ínsula, y le dejase a él por gobernador della. Con estas promesas y otras tales, Sancho Panza, que así se llamaba el labrador, dejó su mujer y hijos y asentó por escudero de su vecino."1

Puede decirse sin faltar a la verdad que Quijote consiguió los servicios de Sancho - sus servicios como escudero para su aventura- so promesa del gobierno de una isla, promesa hija de una tradición que el caballero no demora en explicar:

- Has de saber, amigo Sancho Panza, que fué costumbre muy usada de los caballeros andantes antiguos hacer gobernadores a sus escuderos de las ínsulas o reinos que ganaban, y yo tengo determinado de que por mí no falte tan agradecida usanza; antes pienso aventajarme en ella; porque ellos algunas veces, y quizá las más, esperaban a que sus escuderos fuesen viejos, y ya después de hartos de servir y de llevar malos días y peores noches, les daban algún título de conde, o, por lo mucho, de marqués, de algún valle o provincia de poco más a menos; pero si tú vives y yo vivo, bien podria ser que antes de seis días ganase yo tal reino, que tuviese otros a él adherentes, que viniesen de molde para coronarte por rey de uno dellos. Y no lo tengas a mucho; que cosas y casos acontecen a los tales caballeros, por modos tan nunca vistos ni pensados, que con facilidad te podría dar aún más de lo que te prometo. ${ }^{2}$

En la explicación aparecen dos cosas significativas sobre las cuales nos interesa detenernos: que la isla no es el mayor de los premios que Quijote podría ofrecer a Sancho, y que el premio no es tanto la isla como la cesión de su gobierno.

Sobre el primero de los asuntos, don Quijote no se priva de hacer saber a su flamante escudero explícitamente y desde un primer momento que "...con facilidad..."

\footnotetext{
1 Cervantes Saavedra, M. (1948 [1605]): El ingenioso hidalgo Don Quijote de la Mancha, Primera Parte, Estudio preliminar, edición y notas de Federico de Onís, W. M. Jackson Inc. Editores. Buenos Aires, en adelante, Cervantes, Quijote, Primera Parte, Cap. VII, p. 68.

2 Cervantes, Quijote, Primera Parte, Cap. VII, cit., p. 69, énfasis mío.
} 
podría darle "...aún más..." de lo que le promete. ${ }^{3}$ Pocos días después de su promesa, Quijote rezonga a Sancho mientras le recuerda un elemento muy particular del cual está hecha la misma: que si le diera el gobierno de algo en tierra firme su alegría tendría que ser mayor, a causa de que esto vale más que cualquier ínsula... "-Ya te he dicho, Sancho, que no te dé eso cuidado alguno; que, cuando faltare ínsula, ahí está el reino de Dinamarca, o el de Sobradisa, que te vendrán como anillo al dedo, y más que por ser en tierra firme, te debes más alegrar."4

En esa suerte de economía de la gracia o aritmética del don, tierra firme es más que ínsula y eso lo deja el Quijote muy claro. Pero también es claro que el premio no es la isla sino su gobierno.

Esto lo tiene muy presente Sancho, que inicialmente se preocupa porque "su Mari Gutiérrez",5 según su propia evaluación, no calificaba para reina y a duras penas para condesa. Tenía Sancho poca sal en la mollera y poco aprecio por su esposa, a la cual veía por debajo de su condición. 6 Pero tal operación le permitía replicar el esquema de subordinación patriarcal y doméstica en el cual Quijote acababa de incluirlo a través de la fantasía ya no de un gobierno sino de un reinado, por lo tanto, en un subordinado que había encontrado en su propio ámbito doméstico a quien subordinar; un oprimido que había localizado a quien oprimir.7

En esos aciagos momentos de la novela que no se hacen esperar, Sancho recuerda muy bien aquel segundo aspecto de la promesa fundacional del Quijote. Después del lance con el vizcaíno, del cual Sancho evaluaba que se señor había salido victorioso, el escudero -hincado de rodillas delante suyo- le pidió: "-Mire vuestra merced, señor caballero andante, que no se le olvide lo que de la ínsula me tiene prometido; que yo la sabré gobernar, por grande que sea."8 Tras una segunda escaramuza, donde Quijote perdió parte de una oreja, Sancho volvió a insistir: "- Sea vuestra merced servido, señor don Quijote mío, de darme el gobierno de la ínsula que en esta rigurosa pendencia se ha ganado; que, por grande que sea, yo me siento

\footnotetext{
3 Algo que también emerge de la conversación entre Sancho y el Duque en la Segunda Parte, cuando queda claro que "una tantica parte del cielo..." es más que "...la mayor ínsula del mundo." Cervantes, Quijote, Segunda Parte [1615], Cap. XLII, cit., p. 345.

${ }_{4}^{4}$ Cervantes, Quijote, Primera Parte, Cap. X, cit., pp. 88-89.

${ }^{5}$ Que no es otra que Teresa Panza. Recuérdese que Cervantes utilizó varios nombres para la mujer de Sancho (Mari Gutiérrez y Juana Gutiérrez en la primera parte, Teresa Panza y Teresa Cascajo - en la segunda parte, Cap. V, p. 52, cuando su propia voz ella dice que, si por el apellido de su padre fuera, debiera llamarse Teresa Cascajo.

6 Como en general veía a todas las mujeres la sociedad castellana del momento.

7 Antes de la tercera salida dice Sancho a Quijote que ya tiene relucida a su mujer -a lo cual Quijote le corrige, reducida. Cervantes, Quijote, Segunda Parte, Cap. VII, cit., p. 64.

8 Cervantes, Quijote, Primera Parte, Cap. VII, cit., p. 69.
} 
con fuerzas de saberla gobernar tal y tan bien como otro que haya gobernado ínsulas en el mundo."9 Y terminado el desastre sufrido a manos del ejército de carneros, yendo "...Sancho a su asno para sacar de las alforjas con qué limpiarse y con qué curar a su amo, y como no las halló, estuvo a punto de perder el juicio: maldíjose de nuevo y propuso en su corazón de dejar a su amo y volverse a su tierra, aunque perdiese el salario de lo servido y las esperanzas del gobierno de la prometida ínsula."10

Conforme avanza la novela, el desencanto de Sancho va en aumento y se expresa en varias ocasiones. En Sierra Morena, después de hacerle saber a Don Quijote que no le parecía lógico andar perdidos en esas montañas, Sancho afirmó: "...vengo a imaginar que todo cuanto me dice de caballerías, y de alcanzar reinos e imperios, de dar ínsulas, y de hacer otras mercedes y grandezas, como es uso de caballeros andantes, que todo debe de ser cosa de viento y mentira, y todo pastraña, o patraña, o como lo llamáremos."11

Casi al final de lo que terminó siendo la Primera Parte de este libro, Sancho vuelve sobre la cuestión de la promesa incumplida. Esta vez lo hace para compadecerse de sí mismo y de la triste imagen que daría ante los suyos al cruzar la puerta de su casa familiar pues, "...en lugar del gobernador o visorrey de alguna ínsula o reino, le verán entrar hecho mozo de caballos".12

Sin embargo, Sancho recupera de inmediato su deseo de islas o de gobernar una isla -"...y si ínsulas deseo, otros desean otras cosas peores; y cada uno es hijo de sus obras; $y$, debajo de ser hombre, puedo venir a ser papa, cuanto más gobernador de una ínsula...", así como las esperanzas en su caballero-proveedor "...y más pudiendo ganar tantas mi señor que le falte a quien dallas"13 y una inusitada confianza en sí mismo -" ...por agora estad contenta, que, siendo Dios servido de que otra vez salgamos en viaje a buscar aventuras, vos me veréis presto conde o gobernador de una ínsula, y no de las de por ahí, sino la mejor que pueda hallarse".14 Esta última la obtiene ante el espejo de su mujer -en este capítulo, Juana Panza-15 y es imprescindible para justificarse ante sí y ante su familia para lo que acometerá enseguida, esto es, la segunda parte de una aventura que -nuevamente- le permite

\footnotetext{
9 A la cual respondió don Quijote pidiendo paciencia porque no era esta una aventura de ínsulas sino de encrucijadas "...en las cuales no se gana otra cosa que sacar rota la cabeza o una oreja menos". Cervantes, Quijote, Primera Parte, Cap. X, cit., p. 85.

10 Cervantes, Quijote, Primera Parte, Cap. XVIII, cit., p. 159, énfasis mío.

11 Cervantes, Quijote, Primera Parte, Cap. XXV, cit., p. 235, énfasis mío.

12 Cervantes, Quijote, Primera Parte, Cap. XLVII, cit., p. 502.

13 Cervantes, Quijote, Primera Parte, Cap. XLVII, cit., p. 503.

${ }_{14}$ Cervantes, Quijote, Primera Parte, Cap. XLVII, cit., p. 543.

15 "...que así se llamaba la mujer de Sancho, aunque no eran parientes, sino porque se usa en la Mancha tomar las mujeres el apellido de sus maridos." Cervantes, Quijote, Primera Parte, Cap. XLVII, cit., p. 544 .
} 
alejarse de la labranza tras el sueño del gobierno de una isla.

Antes de salir por tercera vez al ruedo con su caballero, tratando de terminar una difícil discusión con Teresa16 - quien ya ni le cree ni le entiende y desconfía, sobre todo, de la cordura de su marido en particular y, es bueno notarlo, del gobierno en general-, Sancho refrenda: "-Yo os digo, mujer [...] que si no pensara antes de mucho tiempo verme gobernador de una ínsula, aquí me caería muerto."1 7

Sancho había ganado fama en la tierra como "...aquel [...] a quien vuestro amo tiene prometida una ínsula...".18 Pero cumple su sueño en la segunda parte de la obra, publicada en 1615, incluso si para ello no fue necesario que Quijote cumpliera su promesa: el gobierno de dicha ínsula -o mejor dicho, la ficción que todo ello conllevaba- le fue conferido por un duque que organizó todo para su diversión y la de su pequeña corte.

Quijote, en cuanto se enteró de las intenciones del Duque -no de las segundas, por supuesto, sino de las primeras, de conceder a Sancho el gobierno de una ínsulase permitió algunas reflexiones:

...aunque veo en él una cierta aptitud para esto de gobernar, que atusándole tantico el entendimiento, se saldría con cualquiera gobierno como el Rey con sus alcabalas; y más que ya por muchas experiencias sabemos que no es menester ni mucha habilidad en muchas letras para ser uno gobernador, pues hay por ahí ciento que apenas saben leer y gobiernan como unos girifaltes; el toque está en que tengan buena intención y deseen acertar en todo, que nunca les faltará quien les aconseje y encamine en lo que han de hacer, como los gobernadores caballeros y no letrados, que sentencian con asesor. ${ }^{19}$

Frente a la nueva realidad en la cual Sancho ya había sido designado gobernador de una ínsula, Quijote se desplazó de la obligación de proveedor a postularse como asesor de su escudero devenido gobernante. No le pareció mal darle dos tandas de consejos para ejercer el buen gobierno que, desde luego, incluían mayoritariamente sugerencias de honestidad, higiene, templanza, maneras y, por supuesto, de cómo llevar una recta administración de la justicia, que por ahí

\footnotetext{
16 Recuérdese que Cervantes utilizó varios nombres para la mujer de Sancho (Mari Gutiérrez y Juana Gutiérrez en la primera parte, Teresa Panza y Teresa Cascajo -como apellido "de soltera"- en la segunda).

17 Cervantes, Quijote, Segunda Parte, Cap. V, cit., p. 50.

18 Cervantes, Quijote, Segunda Parte, Cap. XXXII, cit., p. 271.

19 Cervantes, Quijote, Segunda Parte, Cap. XXXIII, cit., p. 278-79.
} 
iba el asunto. 20

Sancho tenía dos cosas claras: que ser gobernador era más que ser alcalde; pero también que prefería ir Sancho al cielo que gobernador al infierno. Ambas le ayudarían a pulsar la cuerda de la autoridad tanto como moderar su sed de gobierno, del gobierno de los cuerpos de los otros, de la toma de decisiones que afectaban a los comprendidos en un conflicto, pero también a todas las gentes de su ínsula. Le tomarás el gustito -había sentenciado, predictor, el Duque- "...por ser dulcísima cosa el mandar y ser obedecido".21

Vestido a lo letrado, con un ancho gabán de chamelote y jubón atacado, marchando delante de su basto rucio adornado con seda, Sancho -convencido de que "...en esto de los gobiernos todo es comenzar..."-22 enfila hacia su vida como gobernante. Así fue que "...con todo su acompañamiento llegó Sancho hasta un lugar de hasta mil vecinos, que era de los mejores que el Duque tenía. Diéronle a entender que se llamaba la ínsula Barataria, o ya porque el lugar se llamaba Baratario, o ya por el barato con que se le había dado el gobierno."2 3

Después de entregarle las llaves del pueblo, le condujeron hasta la silla del juzgado y tras un gracioso rito de inicio, Sancho se puso manos a la obra como manda la mejor tradición del buen gobierno: arrancó por aquello de administrar justicia. 24

Los métodos de Sancho no eran ortodoxos, pero el pueblo comenzó a celebrarlos como eficaces. No faltan estudios letrados que caracterizan su estilo de administrar justicia como "...particular y no exento de practicidad..." (Casasola Díaz, 2016: 52) "Quedaron todos admirados y tuvieron a su gobernador por un nuevo Salomón", de donde algunos podían permitirse suponer que quizás Dios realmente

\footnotetext{
20 Cervantes, Quijote, Segunda Parte, Caps. XLII y XLIII.

21 Cervantes, Quijote, Segunda Parte, Cap. XLII, cit., p. 346. El Duque le habla del ejercicio del poder en un sentido despojado de materialidad, es decir, le habla de las mieles de la autoridad y del goce de ser correspondido con la obediencia. La parte crematística del asunto se había filtrado ya en el discurso más íntimo de Sancho, cuando escribe a Teresa, su esposa, anunciándole: "De aquí a pocos días me partiré al gobierno, adonde voy con grandísimo deseo de hacer dineros, porque me han dicho que todos los gobernadores nuevos van con este mesmo deseo...". En contraparte la Duquesa -que leyó la carta de Sancho- le advirtió que "...la codicia rompe el saco, y el gobernador codicioso hace la justicia desgobernada." Cervantes, Quijote, Segunda Parte, Cap. XXXVI, cit., p. 309.

22 Cervantes, Quijote, Segunda Parte, Cap. XXXIII, cit., p. 288.

23 Cervantes, Quijote, Segunda Parte, Cap. XLV, cit., p. 367. También debe considerarse que podría ser por ser "lugar donde se dan baratos o se hacen baratas (ventas dolosas)".

24 La centralidad de la administración de la justicia en el buen gobierno puede encontrarse por supuesto en casi toda la tratadística castellana. Pero es una obra justamente publicada pocos años antes que el Quijote y reeditada enseguida, entre la primera y la segunda parte del mismo, donde mejor y más claramente se encuentra expuesto este concepto.
} 
encamina a los que gobiernan, aunque sean unos tontos. 25 Eso escribió Cervantes.

Por boca de Quijote, Sancho escucha que no debe atribuir la merced que ha recibido a sus méritos, sino que debe dar "gracias al cielo". Sancho había aceptado un típico gobierno delegado de la monarquía católica. Como gobernador sería el máximo juez en su distrito y esto no lo omiten ni el Duque (su mentor) ni Quijote (el caballero que se ha autoerigido en su consejero).

En su primera tanda de consejos -en un acto de violencia dulce- (Hespanha, 1993) le recordó lo rústico que era pero, además, se ocupó de señalarle quiénes estaban todavía más abajo en esa espiral descendiente de rusticidades que se había permitido fabricar solo para él:

Si trujeres a tu mujer contigo [...] enséñala, doctrínala y desbástala de su natural rudeza; porque todo lo que suele adquirir un gobernador discreto suele perder y derramar una mujer rústica y tonta. [...] todo aquello que la mujer del juez recibiere ha de dar cuenta el marido en la residencia universal, donde pagará con el cuatro tanto en la muerte las partidas de que no se hubiere hecho cargo en la vida. 26

Pero de su propia rusticidad no se libraba, toda vez que era completamente analfabeto. Entrando un correo del Duque, el mensajero vociferó que debía recibirla don Sancho en su propia mano o en las de su secretario. Sancho Panza, juezgobernador, necesitaba urgentemente ojos que leyeran para él.

— ¿Quién es aquí mi secretario?

Y uno de los que presentes estaban respondió.

- Yo, señor, porque sé leer y escribir, y soy vizcaíno.

- Con esa añadidura - dijo Sancho-, bien podéis ser secretario del

mismo Emperador. Abrid ese pliego y mirad lo que dice.27

En una misma escena, el completamente iletrado Sancho consigue secretario y nos anuncia, desde una sabiduría incompatible con semejante ignorancia, del aprecio que los vizcaínos intentaban ganarse en los diferentes campos de influencias que se disputaban en la Monarquía y del peso que en esas pujas tenía la cuestión de la escritura. 28

\footnotetext{
25 Cervantes, Quijote, Segunda Parte, Cap. XLV, cit., p. 371.

26 Cervantes, Quijote, Segunda Parte, Cap. XLII, cit., p. 348.

27 Cervantes, Quijote, Segunda Parte, Cap. XLVII, cit., p. 384.

28 "La competencia a lo largo de los siglos XVI y XVII entre vizcaínos y montañeses por espacios de poder en la corte y en las colonias, o por el control de fuentes de riqueza al servicio de la Corona, como la construcción naval o el transporte marítimo, dieron lugar a una producción de tratados o escritos propagandísticos que pugnaban por la primacía de unos u otros. Más allá de la anécdota, esta cuestión se inscribe en un proceso de mayor calado. A lo largo de estos siglos, aquella dinámica al
} 
Las intenciones del gobernador eran explícitas: "...limpiar esta ínsula de todo género de inmundicia y de gente vagamunda, holgazana y mal entretenida; porque quiero que sepáis, amigos, que la gente baldía y perezosa es en la república lo mesmo que los zánganos en las colmenas, que se comen la miel que las trabajadoras abejas hacen."29 La evaluación de la Duquesa, obviamente en sorna, no podía ser más positiva. En una carta que envía a Teresa le escribe. "Tengo noticia que gobierna como un girifalte, de lo que yo estoy muy contenta y el Duque mi señor, por el consiguiente..." $о$ Visita las plazas, aplica la misericordia, persigue a los vagos, se preocupa por la seguridad de su ínsula. Y ensarta refranes, uno detrás de otro, con compulsión. 31

Pero Sancho empieza a sentir el cansancio que le produce la actividad de juez-gobernador en pocos días. "La ocupación [...] es tan grande, que no tengo lugar para rascarme la cabeza...".32 Los miedos -a que le maten o a que ataquen su ínsula por las noches- le quitan el sueño y el mucho trabajo hasta el tiempo para las actividades más elementales: "...no vengas a la hora del comer ni a la del dormir; que los jueces son de carne y de hueso, y han de dar a la naturaleza lo que naturalmente les pide..." 33

¿Cuáles eran aquellas cosas por las que Sancho, durante la novela, ofrece explícitamente renuncia al gobierno de la ínsula? Un reino en tierra firme, el bálsamo de Fierabrás (cap. X, pp. 86-86), una puntica de cielo o el cielo mismo. Esto equivale a decir: el gobierno de un reino mejor, la supresión del dolor, o la salvación. Sin embargo, la razón por la que una vez que lo hubo obtenido y ejercido lo hizo, es completamente diferente. Después de "...la séptima noche de los días de su gobierno...", cuando sus propios gobernados le montaron un simulacro de invasión a

servicio del rey estuvo muy relacionada con prácticas literarias y elaboración de discursos que tuvieron un gran significado para la construcción de una identidad y la escritura de determinada historia provincial y local.", (Imízcoz, 2008: 92).

${ }_{29}$ Cervantes, Quijote, Segunda Parte, Cap. XLIX, cit., p. 401.

зо Cervantes, Quijote, Segunda Parte, Cap. L, cit., p. 414. La frase es un elogio. Y no faltan casos donde Sancho los amerita, como cuando, ante una duda que parecía irresoluble, recordó uno de los preceptos que le diera don Quijote y obró en consecuencia -"que cuando la justicia estuviese en duda, me decantase y acogiese a la misericordia...", Cervantes, Quijote, Segunda Parte, Cap. LI, p. 423.

31 Es curioso, pero se ha señalado justamente que, en este punto, Sancho bien podría ser un espejo de Castillo de Bovadilla.

32 Cervantes, Quijote, Segunda Parte, Cap. LI, cit., p. 426.

3з Cervantes, Quijote, Segunda Parte, Cap. XLIX, cit., p. 399. El tema de la comida es muy importante para Sancho. Más adelante puede leerse: "...denme de comer, y lluevan casos y dudas sobre mí; que yo las despabilaré en el aire", Cervantes, Quijote, Segunda Parte, Cap. LI, p. 423. También es elocuente su preocupación por el método del médico que, para prevenir enfermedades, lo ponía a dieta, “...como si no fuese peor mal la flaqueza que la calentura.", Cervantes, Quijote, Segunda Parte, Cap. LI, p. 426. 
la ínsula por feroces enemigos que lo arrojó a las calles en chanclas y casi desnudo debajo de dos paveses, caído en el suelo boca abajo y convertido en testigo de oídas de una farsa que a todos -menos a él- divertía, Sancho decide marcharse de Barataria. Renuncia a los honores y a la lucha, desilusionado de la vida de gobernador, que le parece demasiado ajetreada, mal pagada y poco preferible a la tranquilidad de su vida como labriego:

-Abrid camino, señores míos, y dejadme volver a mi antigua libertad: dejadme que vaya a buscar la vida pasada, para que me resucite de esta muerte presente. Yo no nací para ser gobernador, ni para defender ínsulas ni ciudades de los enemigos que quisieren acometerlas. Mejor se me entiende a mí de arar y cavar, podar y ensarmentar las viñas, que de dar leyes ni de defender provincias ni reinos. 34

Para prolongar su humillación y así obtener más gozo, el mayordomo del pueblo le recordó que antes tendría que dar residencia. 35 Pero Sancho, afirmado en su pobreza, en su dignidad, y en que solo rendiría cuentas a su Duque, transforma este intento de humillación en más porfía y consigue irse del pueblo tras decir "...que saliendo yo desnudo, como salgo, no es menester otra señal para dar a entender que he gobernado como un ángel." 36

Así parece cumplirse la sentencia de su mujer que, antes de salir le había espetado: "...sin gobierno salistes del vientre de vuestra madre, sin gobierno habéis vivido hasta ahora, y sin gobierno os iréis, o os llevarán, a la sepultura cuando Dios fuere servido." 37

Los juicios admonitorios de Teresa destilaban desprecio por la clase de los que gobernaban, pero también configuraban una mirada realista sobre las capacidades y posibilidades de los pobres. También la culturalmente más arraigada porque, como recuerda Foucault en su clase sobre los hijos de nadie y las ciudadanías en la Grecia clásica, allende y antaño eran los "ricos y poderosos" los que representaban la autoridad política y manejaban, a la vez, el logos y la polis (Foucault, 2010: 119).

A diferencia de lo que sucede con el Ion de Eurípides que, proveniente de la "muchedumbre incapaz" o la "clase desposeída",38 despierta la envidia y la ira de sus

34 Cervantes, Quijote, Segunda Parte, Cap. LIII, cit., p. 440.

35 Rendición de cuentas con formato judicial que, al final de su mandato, debían dar en el sitio donde habían ejercido su gobierno los corregidores, gobernadores y otros oficiales de la monarquía hispánica, tanto en la Península como en América o Filipinas.

${ }_{36}$ Cervantes, Quijote, Segunda Parte, Cap. LIII, cit., p. 442.

37 Cervantes, Quijote, Segunda Parte, Cap. V, cit., p. 50.

38 Así en la edición al cuidado de Carlos García Gual, Esquilo, Tragedias, Vol. II, Gredos, Madrid, 1995. 
pares -mientras que el marido de Teresa, en cualquier caso, fue fugazmente envidiado in absentia por las autoridades del pueblo donde tenía su casa-, el Sancho de Cervantes llega al gobierno de su ínsula porque es un acto literariamente fabricado al que sus también literarios artífices disfrutan como un espectáculo. Sancho juega un rol en un teatro donde se monta la escena de lo imposible para disfrutar con los denuedos a los que sus titiriteros le someten. Ellos y sus cómplices -entre los cuales, muchos de la misma condición de Sancho- lo disfrutan, pero los que pudieran verse en su desgracia reflejados, sin pasar por el territorio de la compasión, reciben no obstante un mensaje pedagógico indudable.

Teresa, además, como si fuera una antropóloga de su propia sociedad, tenía una mirada clara sobre su propia dependencia y sobre las necesidades que como mujer pobre veía estrechamente vinculadas al quehacer de su marido, respecto de la casa y respecto de sí.

—Bien creo yo, marido — replicó Teresa-, que los escuderos andantes no comen el pan de balde; y así, quedaré rogando a Nuestro Señor os saque presto de tanta mala ventura.

—Yo os digo, mujer — respondió Sancho_- que si no pensase antes de mucho tiempo verme gobernador de una ínsula, aquí me caería muerto.

—Eso no, marido mío - dijo Teresa —: viva la gallina, aunque sea con su pepita: vivid vos, y llévese el diablo cuantos gobiernos hay en el mundo [...] Como ésos hay en el mundo que viven sin gobierno, y no por eso dejan de vivir y de ser contados en el número de las gentes. La mejor salsa del mundo es la hambre; y como ésta no falta a los pobres, siempre comen con gusto. Pero mirad, Sancho: si por ventura os viéredes con algún gobierno, no os olvidéis de mí y de vuestros hijos.39

Teresa sabe que más le rinde Sancho inútil pero vivo y cerca que jurisdiccional y lejos. También tiene en mente lo que alguien de su estado debe hacer con su hijo varón y con su hija mujer - a la que prefiere mal casada que bien juntada-. 40

Advertid que Sanchico tiene ya quince años cabales, y es razón que vaya a la escuela, si es que su tío el abad le ha de dejar hecho de la

\footnotetext{
s 9 Cervantes, Quijote, Segunda Parte, Cap. V, cit., p. 50.

40 Sin citar el caso de Sanchica en particular, pero sobre la literatura como espejo de las disposiciones tutelares y patriarcales que alimentaron el derecho español sobre las mujeres hasta bien entrado el siglo XIX (el Código Civil español, que conserva muchas de ellas, rige desde julio de 1889), Enrique Gacto escribió: "Y si la mujer, mientras hija, resultaba una carga indeseable para su padre, no digamos para los maridos, una vez casada.", lo que viene al caso perfectamente (Gacto, 2013: 31)
} 
Iglesia. Mirad también que Mari Sancha vuestra hija no se morirá si la casamos; que me va dando barruntos que desea tanto tener marido como vos deseáis veros con gobierno; $y$, en fin en fin, mejor parece la hija mal casada que bien abarraganada. 41

Teresa Panza demuestra que conoce las cuestiones de la oeconómica del estado llano ${ }^{2}$ y que, incluso si su marido iba a obtener -como ficticiamente obtuvolas mieles del gobierno, la seguridad de su familia pasaba más por el tejido de estos nudos que por los dineros que pudieran llegarle desde la insólita ínsula.

Más de dos siglos antes que Kant y casi cuatro antes que Foucault, Cervantes se había valido de estos personajes para hacerse una de las interrogantes centrales sobre la teoría del gobierno que el Profesor del Collège de France formuló a finales del siglo XX leyendo al filósofo de Königsberg. En el susurro que dice escuchar la Duquesa después de que Sancho hablara un largo rato sobre Don Quijote puede leerse lo siguiente:

- De lo que el buen Sancho me ha contado me anda brincando un escrúpulo en el alma, y un cierto susurro llega a mis oídos, que me dice: 'Pues don Quijote de la Mancha es loco, menguado y mentecato, y Sancho Panza su escudero lo conoce, y, con todo eso, le sirve y le sigue, y va atenido a las vanas promesas suyas, sin duda alguna debe de ser él más loco y tonto que su amo; y siendo esto así, como lo es [...] si al tal Sancho Panza le das ínsula que gobierne; porque el que no sabe gobernarse a sí, ¿cómo sabrá gobernar a otros?'4 3

Cervantes, en la voz de la Duquesa, se adelanta.

Si el poblado gobernado por Sancho era una isla o no lo era, ya se discutía en las propias páginas de El Quijote. Tras escuchar de la voz del cura las noticias que llegaban sobre Sancho a su propio pueblo, incrédulo, el bachiller Sansón Carrasco no muy lejos de Teresa- se pregunta "...qué sería aquello del gobierno de Sancho, y más de una ínsula, siendo todas o las más que hay en el mar Mediterráneo de su

\footnotetext{
41 Cervantes, Quijote, Segunda Parte, Cap. V, cit., pp. 50-51.

42 Para una mirada sobre las cuestiones de la economía de la casa y la influencia de los trabajos de Otto Brunner en español remito al análisis que de las mismas hizo Sanjurjo (2011) tanto como a los posteriores aportes de Agustín Casagrande (2015) y Romina Zamora (2017).

4 s Cervantes, Quijote, Segunda Parte, Cap. XXXIII, cit., p. 284, énfasis mío.
} 
Majestad." A lo que el paje que había traído la carta con unas bellotas de regalo para Teresa, se apuró a conjurar el entuerto: "...de que sea ínsula o no la que gobierna, en eso yo no me entremeto; pero basta que sea un lugar de más de mil vecinos."44

La voz ínsula no figura por ejemplo como entrada en el Diccionario de Covarrubias (publicado a mitad de camino entre la edición de ambas partes de El Quijote) donde sí figura Isla vinculada con su etimología latina, insula, dicitur terra quae undique aquis clauditur, proprie autem in mari. Pero como siempre, y no podía fallar tratándose de islas, Covarrubias nos descubre un tesoro: "No sólo se llaman islas las que están cercadas de aguas, pero también las casas que están edificadas sin que otra ninguna se les pegue, siendo esentas de todas partes."45

Archipiélagos en tierra. Como entendimos en su hora el gobierno de los espacios rurales discontinuos en una llanura del Plata. Así los entendía Covarrubias y de esa naturaleza era la ínsula de Sancho aunque -según cuenta una crónica periodística sobre Alcalá de Ebro, el pueblo en el cual se localiza la mítica Barataria de El Quijote, se pregunta: "¿Qué importa, si el río Ebro se basta por sí solo para convertir Alcalá en isla cuando su caudal aumenta, convirtiendo el meandro que rodea el pueblo en un anillo de agua completo?" (Llamazares, 2015). Cierto es que el régimen de aguas ha cambiado mucho durante estos siglos en la zona, pero también lo es que ni uno solo de los personajes de Cervantes le pone el cascabel al gato de la duda.

La condición insular de la Barataria gobernada por Sancho es muy pronto vinculada con el genio cervantino: ya en 1734, el Diccionario de Autoridades definía ínsula de esta manera: "Se llama en estilo jocoso qualquier Lugar pequeño ù gobierno de poca entidad. Dícese à semejanza de la que fingió Cervantes."46

La segunda acepción de ínsula quedó desde entonces relacionada con lugar pequeño y a un gobierno o, como se atrevió a agregar la edición de Terrero y Pando, incluso un oficio "de poca monta, ó ridiculo."4 7 Algo que contrasta notablemente con la experiencia americana del primer cuarto del siglo XVI, donde las islas fueron objeto de fortísimas disputas toda vez que -claro está, en medio de un océano, y no de la llanura aragonesa- constituían una plataforma para seguir avanzando en la concreción del proyecto expansionista tanto castellano como europeo.

Cervantes, no obstante, nos deja en estas páginas un extraordinario legado que confirma el indudable valor de la literatura como insumo del lenguaje y como

\footnotetext{
${ }_{44}$ Cervantes, Quijote, Segunda Parte, Cap. L, cit., p. 416.

45 Sebastián de Covarrubias, Tesoro de la lengua castellana o española, Edición facsimilar de la editada al cuidado de Martín de Riquer (1943), Alta Fulla, Barcelona, 1998 [1611], p. 742.

46 Diccionario de Autoridades, Madrid, 1734, p. 286.

47 Terreros y Pando, E. (1787): Diccionario castellano con las voces de ciencias y artes y sus correspondientes en las tres lenguas francesa, latina e italiana [...], Tomo segundo, Madrid, Viuda de Ibarra, p. 357.
} 
interpretación de la historia. Don Quijote de la Mancha... es una capa inexorable en el hojaldre de los sentidos de una idea que reúne los conceptos de gobierno e insularidad con una valoración negativa. Un capítulo fundante mucho más allá de cualquier beneficio de inventario, escrito bajo la mirada antropológicamente vigilante de un divertido alter ego cervantino discretamente camuflado en la figura de Teresa Panza.

\section{Bibliografía}

Byrne, S. (2009): "Cervantes y Castillo de Bovadilla", Cervantes: Bulletin of the Cervantes Society of America, 29 (2), pp. 174-190.

Casagrande, A. (2015): "Por una historia conceptual de la Seguridad. Los Alcaldes de Barrio de la Ciudad de Buenos Aires (1770- 1820)”, Conceptos Históricos, 1 (1), pp. 40-71.

Casasola Díaz, J. M. (2016): "De la Ínsula Barataria a las estrellas", eXtoikos, núm. extraordinario 1 (extra), pp. 51-53.

Foucault, M. (2010): El gobierno de sí y de los otros. Buenos Aires, FCE.

Gacto, E. (2013): "Imbecillitas sexus", Cuadernos de Historia del Derecho, 20, pp. 2766.

Hespanha, A. M. (1993): "Sabios y rústicos. La dulce violencia de la razón jurídica", en A. M. Hespanha, La Gracia del Derecho: economía de la cultura en la edad moderna. Madrid, Centro de Estudios Políticos y Constitucionales, pp. 17-60.

Imízcoz, J. M. (2008): "Las élites vasco-navarras y la monarquía hispánica: construcciones sociales, políticas y culturales en la edad moderna", Cuadernos de Historia Moderna, 33, pp. 89-119.

Llamazares, J. (2015): "La ínsula Barataria", El País, Madrid, 22/08/2015, Cultura. Disponible en web: https://elpais.com/cultura/2015/08/22/actualidad

Rodríguez Marín, F., ed. (1920): Rinconete y Cortadillo, Revista de Archivos, Bibliotecas y Museos, Madrid.

Sanjurjo, I. (2011): "La pionera obra de Otto Brunner a través de sus comentaristas", Revista de Historia del Derecho, 42, pp. 155-170. 
Tomás y Valiente, F. (1982): Gobierno e Instituciones en la España del Antiguo Régimen. Madrid, Alianza.

Zamora, R. (2017): Casa poblada y buen gobierno. Oeconomía católica y servicio personal en San Miguel de Tucumán, siglo XVIII. Buenos Aires, Prometeo.

Fecha de recepción: 29 de agosto de 2020

Fecha de aceptación: 2 de octubre de 2020 